\title{
Ultrasound-Assisted Preparation of Brazil Nut Oil-in-Water Emulsions Stabilized by Arabic Gum
}

\author{
Cristyana P. Sena ${ }^{1}$, Renata S. Silva ${ }^{1}$, Luciana A. Junqueira ${ }^{2}$, Daniel D. F. Pereira ${ }^{3}$, Patrícia \\ M. Albuquerque ${ }^{3}$, Ariane Mendonça Kluczkovski ${ }^{4}$, Tatiane P. Souza ${ }^{4}$, Edgar A. Sanches ${ }^{5}$, \\ Amr M. Bakry ${ }^{6}$, Pedro H. Campelo, ${ }^{1, *}$ \\ 1. Faculty of Agrarian Science, Federal University of Amazonas, Manaus, Amazonas, Brazil \\ 2. Department of Food Science, Federal University of Lavras, Lavras MG, Brazil \\ 3. Chemistry Engineering, State University of Amazonas, Manaus, Amazonas, Brazil \\ 4. Faculty of Pharmaceutical Science, Federal University of Amazonas, Manaus, Amazonas, Brazil \\ 5. Nanopol-Laboratory of Nanostructured Polymers, Federal University of Amazonas, Manaus, Amazonas, \\ Brazil \\ 6. College of Food Science and Technology and MOE Key Laboratory of Environment Correlative Dietology, \\ Huazhong Agricultural University, Wuhan, China \\ e-mail: pedrocampelo@ufam.edu.br (P.H. Campelo)
}

Received: 29 October 2018; Accepted: 23 November 2018; Available online: 15 February 2019

\begin{abstract}
The objective of this work is to evaluate the stability of Brazil nut oil emulsions with gum Arabic using ultrasound-assisted homogenization. The emulsions were prepared in a completely randomized design varying the time ( 2 and $4 \mathrm{~min}$ ) and the ultrasound power ( 30 and $40 \%$ ). The physicochemical properties of the emulsions ( $\mathrm{pH}$, conductivity, turbidity, zeta potential, surface tension, rheology and optical microscopy) were evaluated after the homogenization process and 4 hours later. The results showed that more energetic homogenization processes (longer duration and higher ultrasound power) favored the physicochemical properties, keeping the emulsions more stable. Thus, Brazil nut oil emulsions prepared with ultrasound-assisted showed good physic-chemical characteristics that can guarantee good emulsion stability during spray drying, guaranteeing efficiency and protection of the physical and chemical properties of the Brazil nut oil.

Keywords: Brazil nut oil; Emulsions; Ultrasound-Assisted emulsification; Gum Arabic; Surface tension; Turbidity.
\end{abstract}

\section{Introduction}

The Amazon region is of interest to world industry due to its great variety of foods and medicinal plants that have important chemical and biological characteristics to be applied in diverse products and processes [1]. Brazil nut (Bertholletia excelsea) is one of the most important oleaginous fruits of the Amazon region, presenting great nutritional potential, with good levels of unsaturated fatty acids (60-70\%), especially oleic and linoleic acid [2].

Microencapsulation is a process widely used in food science and the main mechanism of which is the packaging of substances into polymer matrices. Spray-drying microencapsulation is the most used for food, with various studies proving its efficiency in maintaining the physicochemical properties of the bioactive compounds [3-5]

Oil-water emulsions are thermodynamically unstable, exhibiting a tendency towards rapid phase separation [6]. Considering from homogenization to the total drying of a food emulsion, it is necessary to ensure that this emulsion is as stable as possible because any destabilization can compromise the final quality of the microparticles. Different biopolymers and more efficient homogenization processes are being studied with the main objective of reducing the destabilization processes of emulsions, preserving their properties for longer periods of time [7]. Ultrasoundassisted homogenization is an extremely efficient process, converting electrical energy into high-energy mechanical waves, breaking the surface of oil into small droplets, forming more stable emulsions for long time periods [8]. Gum Arabic is a carbohydrate with wide use in food, mainly due to its good emulsifying properties [9].

From the above, this work aims to evaluate the stability of Brazil nut oil emulsions with gum Arabic, homogenized through the ultrasound process. The physicochemical properties of the emulsions ( $\mathrm{pH}$, conductivity, turbidity, zeta potential, surface tension, rheology and optical microscopy) will be evaluated after the homogenization process and 4 hours later. This time was chosen because generally the drying process of emulsions 
with food oils is slow and it is necessary to ensure that the properties are maintained without compromising the final quality of the encapsulated oil by spray drying.

\section{Materials and methods}

\subsection{Material}

The Brazil nut (Bertholletia excelsa) oil used in this study was donated by Amazon Oil (Ananindeua, Pará Brazil). Gum Arabic was donated by Alland \& Roberts Ingredients (France).

\subsection{Production of Brazil nut oil emulsions}

Table 1 shows the completely randomized experimental design for the emulsion production. Energy densities (ED) were calculated by using Eq. 1 [10].

$$
E D=\frac{N A P \times t}{V}
$$
$(\mathrm{mL})$.

ED is the energy density $\left(\mathrm{J} \cdot \mathrm{mL}^{-1}\right)$, NAP is the nominal applied power (W), $\mathrm{t}$ is the time (s) and V is the volume

All emulsions were prepared with 25 grams of gum Arabic, 5 grams of oil and 70 grams of distilled water. The gum Arabic solution was prepared and stored at $4{ }^{\circ} \mathrm{C}$ overnight for complete saturation of the biopolymer. Brazil nut oil was added instants before the homogenization process. Aliquots of $40 \mathrm{~mL}$ of emulsion were used using high intensity ultrasound equipment with a $13 \mathrm{~mm}$ diameter probe and $19 \mathrm{kHz}$ frequency (Unique, Desruptor, $800 \mathrm{~W}$, Indaiatuba, Brazil). An ice bath was used to prevent overheating of the samples. All emulsion characterizations were measured shortly after homogenization ( 0 hours) and after an interval of 4 hours. This time interval was chosen because 4 hours is an estimated time from the time the emulsion is prepared to drying for the production of microparticles.

Table 1. Experimental Design of Brazil nut emulsions

\begin{tabular}{llll}
\hline Assay & Time $(\min )$ & Power $(\mathrm{W})$ & Energy Density $\left(\mathrm{J} . \mathrm{mL}^{-1}\right)$ \\
\hline A & 2 & 240 & 288 \\
B & 2 & 320 & 384 \\
C & 4 & 240 & 576 \\
D & 4 & 320 & 768 \\
\hline
\end{tabular}

\subsection{Zeta potential}

The zeta potential of the emulsions was measured using ZetaSizer Nano-ZS equipment (Malvern Instruments, UK). The emulsions were diluted in Milli-Q water until ideal equipment detection. The measurements were performed in triplicate (each measure with 10 runs or more) at $25^{\circ} \mathrm{C}$ [8].

\subsection{Droplet size}

Emulsions droplet sizes were measured by laser light scattering method in a Mastersizer 2000 (Malvern Instruments, Worcestershire, England, UK). The measurements were performed in triplicate at $25^{\circ} \mathrm{C}$. The mean diameter of the droplets was expressed as the surface volume or Sauter diameter $\left(\mathrm{d}_{32}\right)$ and calculated by using Eq. 2. To determine the variations in the droplet size distributions, a term known as the PDI (polydispersity index) was calculated by using Eq. 3:

$$
\begin{aligned}
& d_{3,2}=\frac{\sum n_{i} d_{i}^{3}}{\sum n_{s} d_{i}^{2}} \\
& P D I=\frac{d(90)-d(10)}{d(50)}
\end{aligned}
$$

where $n_{\mathrm{i}}$ is the number of droplets of diameter $\mathrm{d}_{\mathrm{i}} ; \mathrm{d}(10), \mathrm{d}(50)$, and $\mathrm{d}(90)$ are the diameters at $10 \%, 50 \%$, and $90 \%$ cumulative volume, respectively.

\subsection{Surface tension}

The surface tension of the Brazil nut oil emulsions was obtained in a ring tensiometer (Kruss, model K12, Germany). The measurements were performed in triplicate (each measure with 5 runs or more) at $25^{\circ} \mathrm{C}[11]$. 


\section{$2.6 \mathrm{pH}$ and conductivity}

Emulsion $\mathrm{pH}$ was measured using a PHS-3E $\mathrm{pH}$ meter (pHTek, Curitiba, Brazil). The equipment was calibrated with buffer solutions, and $\mathrm{pH}$ values were measured by inserting the electrode directly into the sample at $25^{\circ} \mathrm{C}$. The emulsion electrical conductivity was measured using a benchtop conductivity meter (Hanna, model HI 8731, Portugal). The conductivity values were measured by inserting the electrode directly into the sample at $25^{\circ} \mathrm{C}$. All measurement were in triplicate [12].

\subsection{Turbidity}

The emulsion turbidity was measured as nephelometric turbidity units (NNU) at $90^{\circ}$ light scattering and 860 nm with a turbidometer (Plus II, Alfakit, Brazil) [13].

\subsection{Rheology}

Emulsion rheology was analyzed in a concentric cylinder viscometer (Brookfield DVIII, Brookfield Engineering Laboratories, USA), maintaining the emulsions at $25^{\circ} \mathrm{C}$ using a thermostatic bath. The data were adjusted to the Power Law model (Eq. 4) to analyze the emulsion flow properties.

$$
\sigma=k \cdot \gamma^{n}
$$

where $\sigma=$ shear stress $(\mathrm{Pa}), \gamma=$ shear rate $\left(\mathrm{s}^{-1}\right), \mathrm{k}=$ consistency index $\left(\mathrm{Pa} \cdot \mathrm{s}^{\mathrm{n}}\right)$, and $\mathrm{n}=$ flow behavior index.

\subsection{Optical microscopy}

The analysis was performed in an Axio Scope A1 optic microscope, Carl Zeiss (Germany), with a video camera attached. For this, an aliquot of emulsion was placed on the slide, covered with a cover slip, and examined with a 100x objective lens.

\subsection{Statistical analysis}

Analysis of variance (ANOVA) and rheological data adjustment to rheological models were performed using $\mathrm{R}$ software. Significant differences between the samples $(\mathrm{p}<0.05)$ were assessed by the Scott-Knott mean comparison test.

\section{Results and discussion}

\subsection{Zeta potential}

Zeta potential is one of the most commonly used parameters in emulsion stability studies. Emulsions present two types of stabilization mechanisms [14]: the steric mechanism, in which the stability is due to adhesion of the emulsifier to the surface of the droplets; and the electrostatic mechanism, in which stability is associated with electrostatic repulsion of the surface charges of the particles. Emulsions are considered stable by the electro-static mechanism when the zeta potential values are greater than $\pm 30 \mathrm{mV}$, imparting resistance to droplet aggregation [15]. Fig. 1a shows the zeta potential for Brazil nut oil emulsions. In general, zeta potential values were greater than $-30 \mathrm{mV}$, confirming the steric mechanism was not dominant in the stability of Brazil nut oil emulsions. Studies with oil rich in D-limonene and gum Arabic also demonstrated $\theta$ that the dominant emulsion stabilization mechanism was steric [16]. Note that time and power significantly interfered with zeta potential values, presenting higher values with increased time and ultrasound power. The cavitation process can break the biopolymer chains, increasing the surface charge due to the formation of free radicals [17].

\subsection{Surface tension}

Fig. $1 \mathrm{~b}$ shows the surface tension values for Brazil nut oil emulsions. As expected, the surface tension values were lower than those for pure water [18]. All treatments, except assay A, presented significant difference for the surface tension values, that is, during the 4 hours of storage. High energy homogenization processes favor the formation of smaller droplets and, consequently, increase the surface tension due to the increase of the frictional force between the droplets caused by the large surface area. When the surface tension decreases, it may result in accumulation of emulsion oil droplets at the air/emulsion interface (cream). This droplet accumulation on the surface induces a decrease in the surface tension value due to the lower surface tension of the oil [19].

In general, emulsions with gum Arabic showed low surface tension reduction values. Studies of emulsions with gum Arabic and sweet almond oil also resulted in little variation of the surface tension values during the first 24 hours [20]. Gum Arabic has good ability to lower the surface tension between water and oil, forming more stable 
emulsions [21]. A good emulsifier should bind easily at the interface created during homogenization, reducing surface tension to facilitate droplet breakage [22].
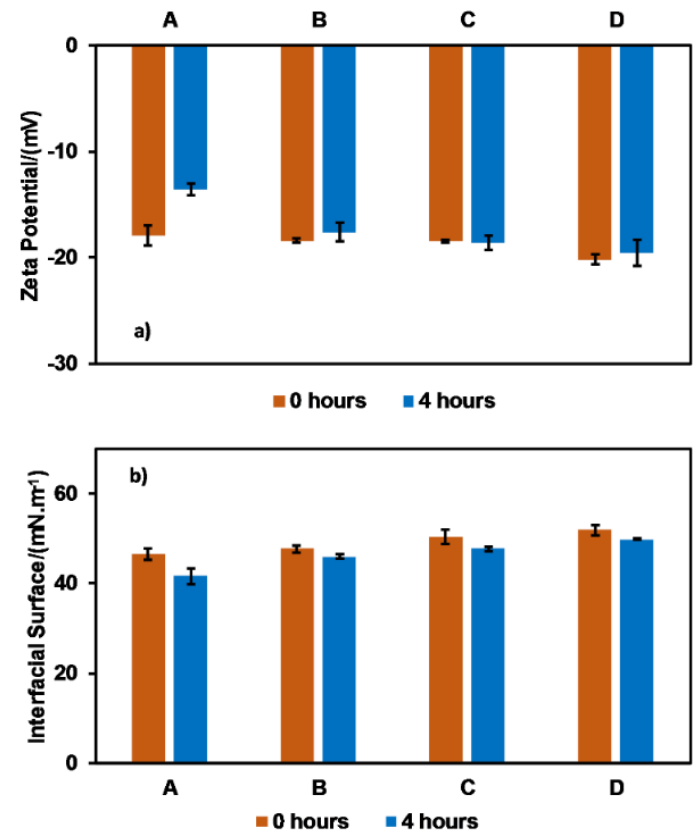

Fig. 1. Zeta potential (a) and interfacial tension (b) to Brazil nut oil emulsions. $A=288 \mathrm{~J} \cdot \mathrm{mL}^{-1}, B=384 \mathrm{~J} \cdot \mathrm{mL}^{-1}$, $\mathrm{C}=576 \mathrm{~J} \cdot \mathrm{mL}^{-1}, \mathrm{D}=768 \mathrm{~J} \cdot \mathrm{mL}^{-1}$.

\section{$3.3 \mathrm{pH}$, conductivity and turbidity}

The $\mathrm{pH}$ and conductivity values of Brazil nut oil emulsions are shown in Table 2. The $\mathrm{pH}$ is an important factor in emulsion stability studies since its variation may indicate chemical changes in the emulsions [8]. Note that $\mathrm{pH}$ results did not vary significantly $(p>0.05)$ regardless of process time and potency and during 4 hours of storage and may be indicative of emulsion stability. That is, the high energy of the cavitation process did not damage the molecular structure of the biopolymers, maintaining the emulsion more stable. In general, emulsions have $\mathrm{pH}$ values between 2.5 - 7.5 [23]. Other authors have observed $\mathrm{pH}$ values that corroborate those of this study for lime [8] and orange [24] essential emulsions. Regarding the conductivity values (Table 2), it is noticed that only for the treatment with lower energy (treatment A) was there significant change after 4 hours of storage. In emulsions containing orange oil and gum Arabic, other authors [24] observed conductivity values in the range from 0.087 $0.179 \mathrm{mS} . \mathrm{cm}^{-1}$, values well below those observed in this present study. This behavior can be explained by the formation of free radicals during homogenization due to the high energy cavitation process [25]. The formation of free radicals may favor the increase of surface charges and increase emulsion stability, confirmed by the zeta potential values observed in Fig. 1.

Table 2. pH, conductivity and turbidity to Brazil nut oil emulsions.

\begin{tabular}{lcccccc}
\hline \multirow{2}{*}{ Assay } & $\mathrm{pH}$ & \multicolumn{2}{c}{ Conductivity $\left(\mathrm{mS.cm}{ }^{-1}\right)$} & \multicolumn{2}{c}{ Turbidity (NTU) } \\
\cline { 2 - 7 } & 0 hours & 4 hours & 0 hours & 4 hours & $0 \mathrm{~h}$ & $4 \mathrm{~h}$ \\
\hline A & $4.68 \pm 0.1^{\mathrm{a}}$ & $4.64 \pm 0.12^{\mathrm{a}}$ & $2.73 \pm 0.01^{\mathrm{a}}$ & $2.64 \pm 0.02^{\mathrm{b}}$ & $136.1 \pm 1.3^{\mathrm{b}}$ & $115.9 \pm 3.48^{\mathrm{c}}$ \\
$\mathrm{B}$ & $4.62 \pm 0.2^{\mathrm{a}}$ & $4.61 \pm 0.2^{\mathrm{a}}$ & $2.73 \pm 0.02^{\mathrm{a}}$ & $2.78 \pm 0.08^{\mathrm{a}}$ & $156.1 \pm 1.5^{\mathrm{a}}$ & $154.6 \pm 3.27^{\mathrm{a}}$ \\
$\mathrm{C}$ & $4.66 \pm 0.2^{\mathrm{a}}$ & $4.62 \pm 0.3^{\mathrm{a}}$ & $2.73 \pm 0.03^{\mathrm{a}}$ & $2.73 \pm 0.03^{\mathrm{a}}$ & $173.3 \pm 3.3^{\mathrm{a}}$ & $167.7 \pm 1.55^{\mathrm{a}}$ \\
$\mathrm{D}$ & $4.61 \pm 0.1^{\mathrm{a}}$ & $4.6 \pm 0.17^{\mathrm{a}}$ & $2.87 \pm 0.01^{\mathrm{a}}$ & $2.72 \pm 0.06^{\mathrm{a}}$ & $142.1 \pm 1.1^{\mathrm{b}}$ & $144.3 \pm 4.8^{\mathrm{b}}$ \\
\hline
\end{tabular}
deviation. a) $288 \mathrm{~J} . \mathrm{mL}^{-1}$, b)384 J.mL ${ }^{-1}$, c) $576 \mathrm{~J} \cdot \mathrm{mL}^{-1}$, d) $768 \mathrm{~J} \cdot \mathrm{mL}^{-1}$.

Emulsion turbidity is directly related to the droplet size and the material concentration in the solution [26]. Therefore, the change in turbidity values may be associated with a change in droplet size over time [27]. It is noteworthy that the turbidity values (Table 2) for the emulsions were high, mainly due to the high concentration of gum Arabic used ( $25 \%$ of emulsions), with significant variation only for the treatment of lower energy density 
(2/30). In studies with emulsions with orange oil and gum Arabic [12] high turbidity was observed with increasing solids concentration in the emulsion.

\subsection{Droplet size}

The magnitude of the interactions and repulsive forces between the emulsion droplets plays a positive role in the stability of emulsions. However, the mean droplet size increase over time, because of flocculation, coalescence and aggregation, may be responsible for increased turbidity during storage [12]. Table 3 shows the droplet size values and the polydispersion index (PDI) for Brazil nut oil emulsion. Generally, food emulsions have droplet size in the range from 0.1 to $100 \mu \mathrm{m}$ [7]. The processes with less homogenization time $(2 / 30$ and 2/40) showed greater destabilization of the emulsions with a significant increase $(\mathrm{p}<0.05)$ in droplet size. In coconut oil emulsion [28] and palm oil [29] studies, the authors observed that increasing the time and power of the ultrasonic homogenization reduced the oil droplet size. Campelo et al. (2017) also observed a significant increase in droplet size for lemon essential oil emulsions with gum Arabic. Emulsions formed by ultrasound have a smaller droplet size than found with mechanical homogenization methods due to the process being more energetic, favoring the oil breakage into smaller droplets [30].

Table 3. Droplet size and PDI values to Brazil nut oil emulsions.

\begin{tabular}{|c|c|c|c|c|}
\hline \multirow{2}{*}{ Assay } & \multicolumn{2}{|c|}{ Droplet size $(\mu \mathrm{m})$} & \multicolumn{2}{|l|}{ PDI } \\
\hline & 0 hours & 4 hours & 0 hours & 4 hours \\
\hline A & $0.47 \pm 0.10^{\mathrm{b}}$ & $0.56 \pm 0.11^{\mathrm{a}}$ & $1.11 \pm 0.21^{\mathrm{b}}$ & $1.59 \pm 0.02^{b}$ \\
\hline B & $0.47 \pm 0.10^{\mathrm{b}}$ & $0.62 \pm 0.05^{\mathrm{a}}$ & $1.42 \pm 0.21^{\mathrm{a}}$ & $1.50 \pm 0.05^{\mathrm{a}}$ \\
\hline $\mathrm{C}$ & $0.32 \pm 0.14^{\mathrm{b}}$ & $0.62 \pm 0.01^{\mathrm{b}}$ & $1.27 \pm 0.13^{\mathrm{a}}$ & $1.48 \pm 0.02^{\mathrm{a}}$ \\
\hline $\mathrm{D}$ & $0.30 \pm 0.04^{\mathrm{d}}$ & $0.50 \pm 0.02^{\mathrm{b}}$ & $1.21 \pm 0.04^{\mathrm{c}}$ & $1.32 \pm 0.01^{\mathrm{c}}$ \\
\hline
\end{tabular}

a,b Same letter in same column represents no significant difference $(\mathrm{p}>0.05)$. Results are presented as the mean \pm standard deviation. $\mathrm{A}=288 \mathrm{~J} \cdot \mathrm{mL}^{-1}, \mathrm{~B}=384 \mathrm{~J} \cdot \mathrm{mL}^{-1}, \mathrm{C}=576 \mathrm{~J} \cdot \mathrm{mL}^{-1}, \mathrm{D}=768 \mathrm{~J} \cdot \mathrm{mL}^{-1}$.

The PDI is related to the homogeneity of the particle size, that is, the lower the PDI value, the more homogeneous the particle size distribution. It can be observed (Table 3) that the emulsions with low time and potency presented high PDI values, showing that less energetic homogenization processes may form differentsized droplets, and may favor the destabilization of emulsions due to the agglomeration of oil droplets. During the 4 hours of storage, the PDI values showed no significant variation, and it can be confirmed that the emulsions did not change significantly as to the droplet size distribution. It was observed in studies of palm oil [29] and coconut oil [28] emulsions, using assisted ultrasound, that the increase of time and potency of homogenization favored the formation of a more homogeneous distribution profile. Silva et al. (2015) observed high PDI values for low energy homogenized annatto oil and gum Arabic emulsions.

Fig. 2 shows the distribution profile of droplet size for Brazil nut oil emulsions. It is noted that the increase in ultrasound power and the homogenization time improved the droplet size distribution, making them more uniform. Homogenization with low energy presented bimodal behavior, while the processes with more energy presented a more normalized profile. After 4 hours, the distribution profiles tend to increase the mean value of the droplets and the distribution is more heterogeneous. Abismail et al. [31] cited that ultrasound-assisted emulsions are less polydisperse and more stable.

\subsection{Rheology}

The rheological behavior of Brazil nut oil emulsions is shown in Fig 3. Note that the increase in homogenization energy resulted in increased shear stress. This can be explained by an increase of the contact surface with the formation of smaller droplets, increasing the frictional force between the particles and thus increasing the force needed for shear. These results are confirmed by the increase in surface tension (Figure 3) and the smaller size (Table 3) of droplets for ultrasonic homogenization processes with higher energy. Furthermore, it can be seen that the D treatment had the greatest viscosity difference for the fresh emulsion and that stored after 4 hours. Carbohydrates are often added to the emulsions as thickening agents because of their ability to increase viscosity and thus delay destabilization [29]. The rheological changes that can occur in the emulsions after the preparation period are mainly associated to the destabilization processes, since in these processes the oil is released to the continuous phase, changing the rheological properties of the system [22].

The power law (Table 3) presented a good fit for the rheological data of Brazil nut oil emulsions $\left(\mathrm{R}^{2}>0.99\right)$. All emulsions presented a Flow behavior index (n) close to 1, showing that the systems present behavior of Newtonian fluids, with a linear relationship between the shear stress and the shear rate. The consistency index $(\mathrm{k})$ 
of the emulsions showed that the emulsions with the highest sonication time and potency showed more viscous behavior, related to the reduction of the droplet size due to the high shear in the process [32]. Gum Arabic tends to present more viscous emulsions due to the high protein content with an associated greater water retention and binding capacity at the water-oil interface [33]. The relationship between the apparent viscosity and the shear rate of the Brazil nut oil emulsions are presented in Figure 6. Extreme factors of the ultrasonic-assisted homogenization process, mainly related to the high shear rate, may be associated with the significant increase in apparent viscosity of emulsions [22].
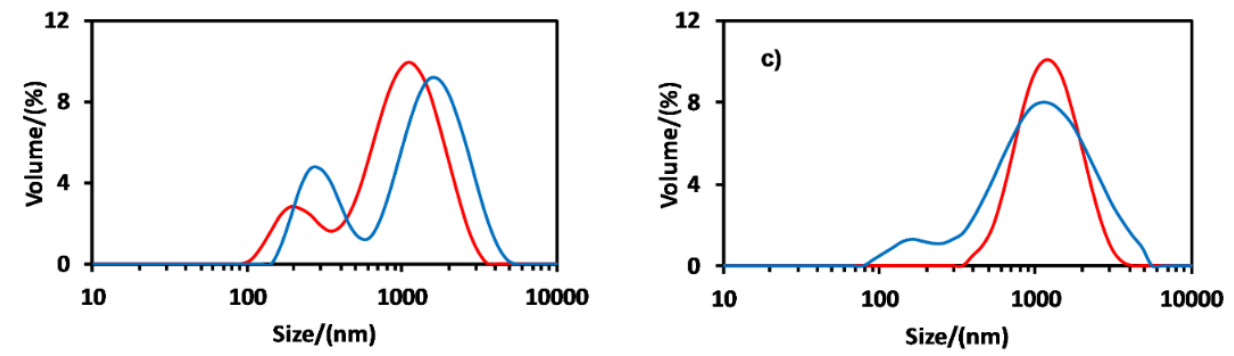

$-2 / 30-0 h \quad-2 / 30-4 h$
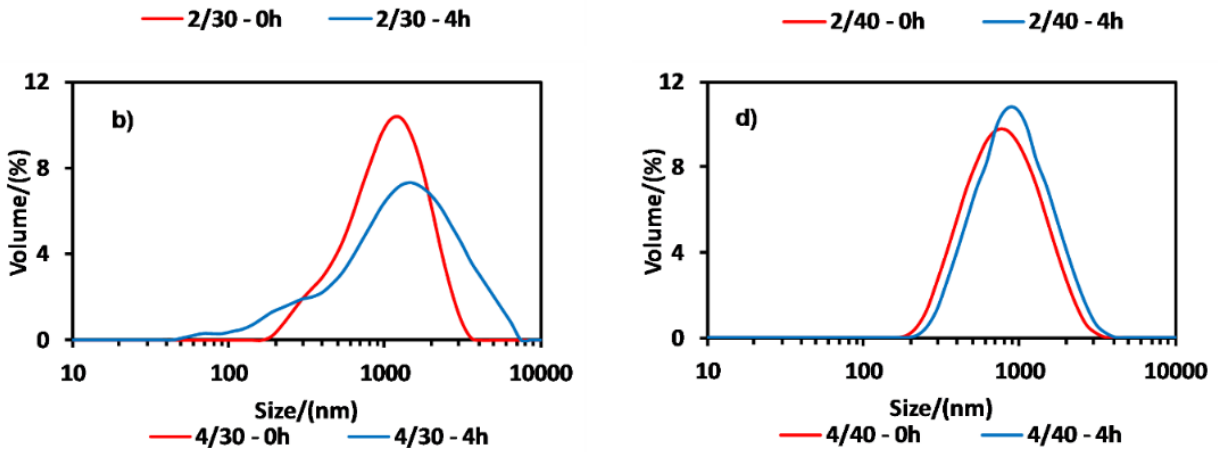

Fig. 2. Droplet size distribution of Brazil nut oil emulsions. a) $288 \mathrm{~J} . \mathrm{mL}^{-1}$, b) $384 \mathrm{~J} . \mathrm{mL}^{-1}$, c) $576 \mathrm{~J} . \mathrm{mL}^{-1}$,d) 768 J.mL $L^{-1}$.
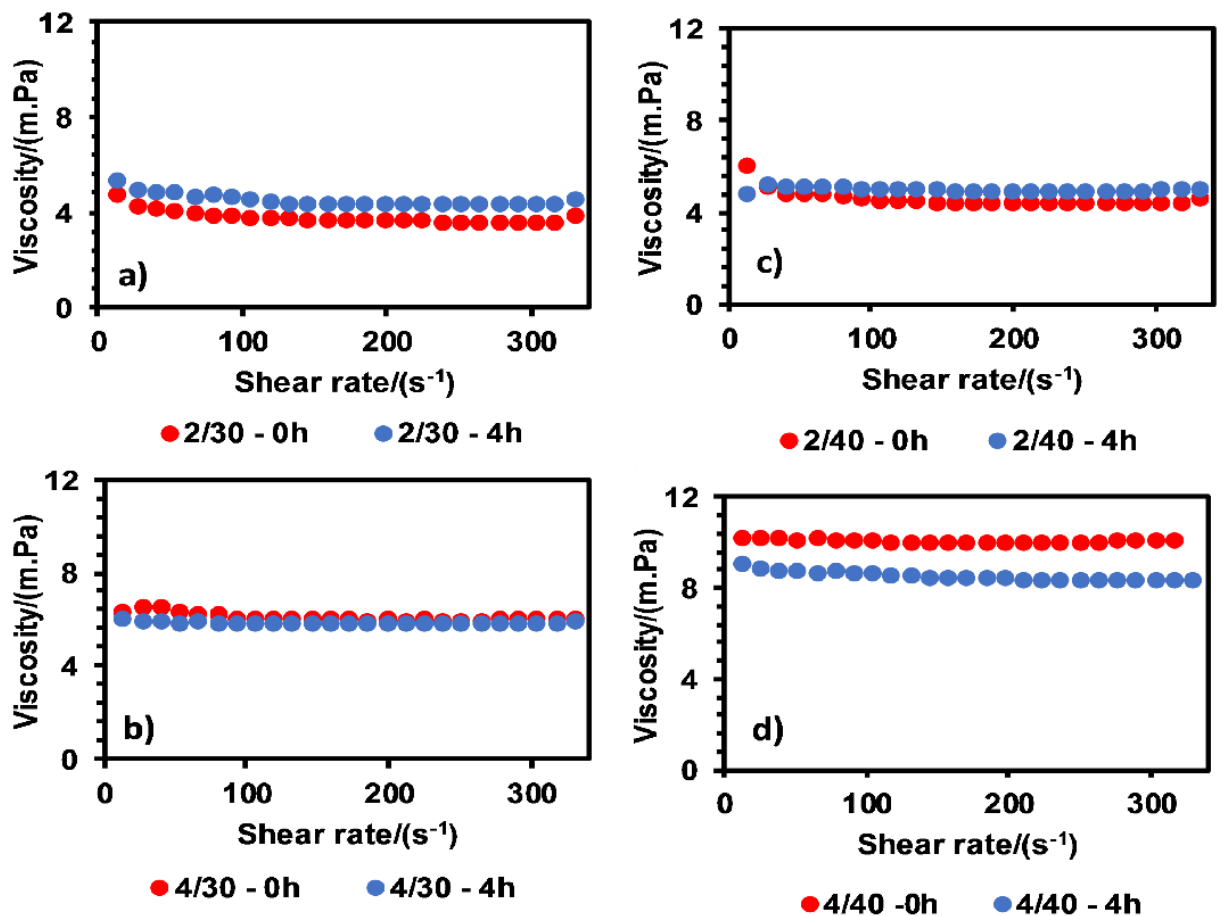

Fig. 3. Shear stress profile in function to shear rate to Brazil nut oil emulsions. a) $288 \mathrm{~J} . \mathrm{mL}^{-1}$, b) $384 \mathrm{~J} . \mathrm{mL}^{-1}$, c) 576 J.mL ${ }^{-1}$,d) 768 J.mL ${ }^{-1}$. 


\subsection{Optical microscopy}

Optical microscopy images of the emulsions (Fig. 4) shows the increase in droplet size after 4 hours of storage. Note that droplet size is lower for higher energy homogenization processes (C and D) with little agglomeration of droplets, confirming the data in Table 2. In studies with emulsions of lemon and gum Arabic essential oil (Campelo et al., 2017) behavior similar to that of the present study was observed.
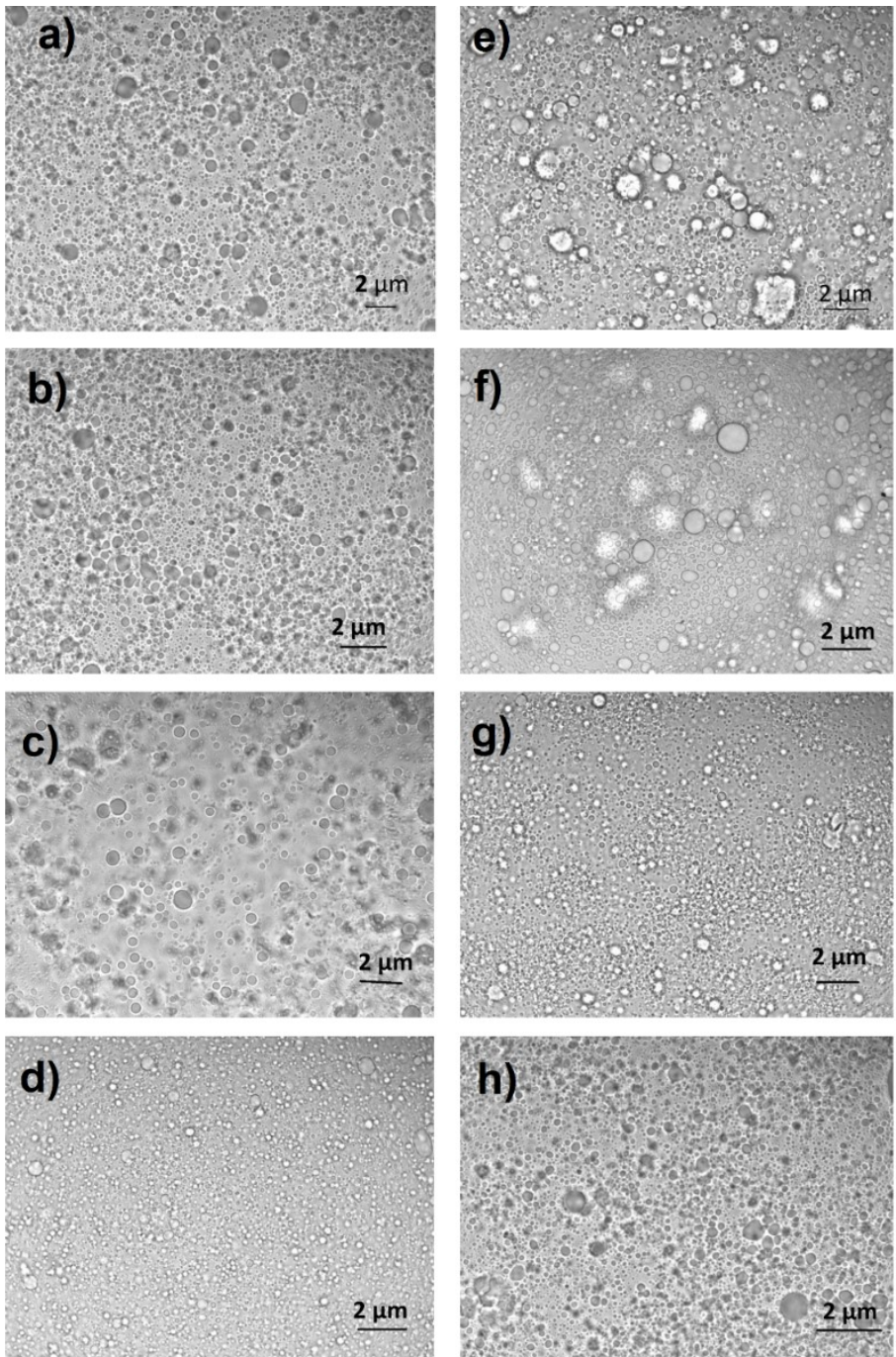

Fig. 4. Microscopy images of Brazil nut oil emulsions. a) $288 \mathrm{~J} . \mathrm{mL}^{-1}$, b) $384 \mathrm{~J} \cdot \mathrm{mL}^{-1}$, c) $576 \mathrm{~J} . \mathrm{mL}^{-1}$, d) $768 \mathrm{~J} . \mathrm{mL}^{-1}$ to 0 hours and e) $288 \mathrm{~J} \cdot \mathrm{mL}^{-1}$, f) $384 \mathrm{~J} \cdot \mathrm{mL}^{-1}$, g) $576 \mathrm{~J} \cdot \mathrm{mL}^{-1}$, h) $768 \mathrm{~J} \cdot \mathrm{mL}^{-1}$ to 4 hours

\section{Conclusions}

We performed a study on the influence of the process parameters of ultrasonic homogenization of Brazil nut oil and gum Arabic emulsions. We found that the increase in potency and time favored the formation of emulsions with reduced droplet size. Small droplets can favor emulsion stability, increasing the viscosity and surface tension of the medium, hindering destabilization processes such as oil droplet flocculation and agglomeration. The $\mathrm{pH}$ and conductivity values did not vary significantly and could be a good tool to confirm the stability of emulsions. The zeta potential confirmed that the preponderant stabilization mechanism of the emulsions was steric. Thus, Brazil nut oil emulsions, prepared with ultrasound, showed good physicochemical characteristics that can guarantee good emulsion stability during spray-drying, guaranteeing efficiency and protection of the oil physical and chemical properties.

\section{Acknowledgments}

The authors are grateful to Amazon Oil and Alland \& Roberts for donation of Brazil nut oil and gum Arabic, respectively. 


\section{References}

[1] C.G. de S. Guerra, J.P.L. Aguiar, W.L.P. Duncan, A.M. Kluczkovski, F. das C. do A. Souza. Effect of Brazil nut oil (Bertholletia excelsa HBK) on the physical, chemical, sensory and microbiological characteristics of a mayonnaise-type emulsion. African J. Biotechnol. 2017;16:657-663.

[2] O.V. Santos, N.C.F. Corrêa, F.A.S.M. Soares, L.A. Gioielli, C.E.F. Costa, S.C.S. Lannes. Chemical evaluation and thermal behavior of Brazil nut oil obtained by different extraction processes. Food Res. Int. 2012;47:253-258.

[3] R.V.B. Fernandes, S. V. Borges, D.A. Botrel, E.K. Silva, J.M.G. Costa, F. Queiroz. Microencapsulation of Rosemary Essential Oil: Characterization of Particles. Dry. Technol. 2013; 31:1245-1254.

[4] E.C. Frascareli, V.M. Silva, R. V. Tonon, M.D. Hubinger. Effect of process conditions on the microencapsulation of coffee oil by spray drying. Food Bioprod. Process. 2012;90: 413-424.

[5] D.R.S.F. Paim, S.D.O. Costa, E.H.M. Walter, R. V. Tonon. Microencapsulation of probiotic jussara (Euterpe edulis M.) juice by spray drying. LWT - Food Sci. Technol. 2016;74: 21-25.

[6] D.J. McClements, L. Bai, C. Chung. Recent Advances in the Utilization of Natural Emulsifiers to Form and Stabilize Emulsions. Annu. Rev. Food Sci. Technol. 2017;8:205-236.

[7] D.J. McClements. Critical review of techniques and methodologies for characterization of emulsion stability. Crit. Rev. Food Sci. Nutr. 2007;47: 611-649.

[8] P.H. Campelo, L.A. Junqueira, J.V. de Resende, R.D. Zacarias, R.V. de B. Fernandes, D.A. Botrel, S. V. Borges. Stability of lime essential oil emulsion prepared using biopolymers and ultrasound treatment. Int. J. Food Prop. 2017: 1-16.

[9] A.J. Al-Mosawi, F. Thevenet. Acacia gum (gum arabic). Blackwell Publishing; 2006.

[10] M.T.M.G. Rosa, E.K. Silva, D.T. Santos, A.J. Petenate, M.A.A. Meireles. Obtaining annatto seed oil miniemulsions by ultrasonication using aqueous extract from Brazilian ginseng roots as a biosurfactant. J. Food Eng. 2016;168: 68-78.

[11] M. Aghbashlo, H. Mobli, A. Madadlou, S. Rafiee. The correlation of wall material composition with flow characteristics and encapsulation behavior of fish oil emulsion. Food Res. Int. 2012;49: 379-388.

[12] H. Mirhosseini, C.P. Tan, N.S.A. Hamid, S. Yusof. Optimization of the contents of Arabic gum, xanthan gum and orange oil affecting turbidity, average particle size, polydispersity index and density in orange beverage emulsion. Food Hydrocoll. 2008;22:1212-1223.

[13] M. Hosseinnia, M.A. Khaledabad, H. Almasi. Optimization of Ziziphora clinopodiodes essential oil microencapsulation by whey protein isolate and pectin: A comparative study. Int. J. Biol. Macromol. 2017;101: 958-966.

[14] T.P. Sari, B. Mann, R. Kumar, R.R.B. Singh, R. Sharma, M. Bhardwaj, S. Athira. Preparation and characterization of nanoemulsion encapsulating curcumin. Food Hydrocoll. 2015;43:540-546.

[15] H.D. Silva, M.A. Cerqueira, A.A. Vicente. Nanoemulsions for Food Applications: Development and Characterization. Food Bioprocess Technol. 2012; 5:854-867.

[16] M.. Jayme, D.. Dunstan, M.. Gee. Zeta potentials of gum arabic stabilised oil in water emulsions. Food Hydrocoll. 1999;13:459-465.

[17] W.D. O’Brien. Ultrasound-biophysics mechanisms. Prog. Biophys. Mol. Biol. 2007;93: 212-255.

[18] A. Jiménez, L. Sánchez-González, S. Desobry, A. Chiralt, E.A. Tehrany. Influence of nanoliposomes incorporation on properties of film forming dispersions and films based on corn starch and sodium caseinate. Food Hydrocoll. 2014; 35: 159-169.

[19] M. Kaci, E. Arab-Tehrany, I. Desjardins, S. Banon-Desobry, S. Desobry. Emulsifier free emulsion: Comparative study between a new high frequency ultrasound process and standard emulsification processes. J. Food Eng. 2017;194:109-118.

[20] E. Bouyer, G. Mekhloufi, I. Le Potier, T. du F. de Kerdaniel, J.L. Grossiord, V. Rosilio, F. Agnely. Stabilization mechanism of oil-in-water emulsions by $\beta$-lactoglobulin and gum arabic. J. Colloid Interface Sci. 2011; 354: 467-477.

[21] E. Dickinson, B.S. Murray, G. Stainsby, D.M.W. Anderson. Surface activity and emulsifying behaviour of some Acacia gums. Top. Catal. 1988;2: 477-490.

[22] E.K. Silva, M.T.M.S. Gomes, M.D. Hubinger, R.L. Cunha, M.A.A. Meireles. Ultrasound-assisted formation of annatto seed oil emulsions stabilized by biopolymers. Food Hydrocoll. 2015;47: 1-13.

[23] D.J. McClements. Food Emulsion: Principle, Practices, and Techniques, Second. Boca Raton: CRC Press; 2005.

[24] H. Mirhosseini, C.P. Tan, N.S.A. Hamid, S. Yusof. Effect of Arabic gum, xanthan gum and orange oil contents on $\zeta$-potential, conductivity, stability, size index and $\mathrm{pH}$ of orange beverage emulsion. Colloids Surfaces A: Physicochem. Eng. Asp. 2008;315: 47-56.

[25] A.R. Jambrak, T.J. Mason, V. Lelas, Z. Herceg, I.L. Herceg. Effect of ultrasound treatment on solubility and 
foaming properties of whey protein suspensions. J. Food Eng. 2008;86: 281-287.

[26] S.R. Reddy, H.S. Fogler. Emulsion stability: Determination from turbidity. J. Colloid Interface Sci. 1981; 79:101-104.

[27] P.H. Li, W.C. Lu. Effects of storage conditions on the physical stability of d-limonene nanoemulsion. Food Hydrocoll. 2014;53:218-224.

[28] K.A. Ramisetty, A.B. Pandit, P.R. Gogate. Ultrasound assisted preparation of emulsion of coconut oil in water: Understanding the effect of operating parameters and comparison of reactor designs. Chem. Eng. Process. Process Intensif. 2015;88: 70-77.

[29] L. Consoli, G. de Figueiredo Furtado, R.L. da Cunha, M.D. Hubinger. High solids emulsions produced by ultrasound as a function of energy density. Ultrason. Sonochem. 2017;38:772-782.

[30] O. Krasulya, V. Bogush, V. Trishina, I. Potoroko, S. Khmelev, P. Sivashanmugam, S. Anandan. Impact of acoustic cavitation on food emulsions. Ultrason. Sonochem. 2016;30:98-102.

[31] B. Abismaïl, J.P. Canselier, A.M. Wilhelm, H. Delmas, C. Gourdon. Emulsification by ultrasound: Drop size distribution and stability. Ultrason. Sonochem. 1999;6:75-83.

[32] E.K. Silva, M.A.A. Meireles. Influence of the degree of inulin polymerization on the ultrasound-assisted encapsulation of annatto seed oil. Carbohydr. Polym. 2015; 133:578-586.

[33] R.V.B. Fernandes, S. V. Borges, E.K. Silva, Y.F. da Silva, H.J.B. de Souza, E.L. do Carmo, C.R. de Oliveira, M.I. Yoshida, D.A. Botrel. Study of ultrasound-assisted emulsions on microencapsulation of ginger essential oil by spray drying. Ind. Crops Prod. 2016;94:413-423.

(C) 2019 by the author(s). This work is licensed under a Creative Commons Attribution 4.0 International License (http://creativecommons.org/licenses/by/4.0/). Authors retain copyright of their work, with first publication rights granted to Tech Reviews Ltd. 